\title{
Controlled Hypercapnia and Neonatal Cerebral Artery Doppler Ultrasound Waveforms
}

\author{
L. N. J. ARCHER, D. H. EVANS, J. Y. PATON, AND M. I. LEVENE \\ Departments of Child Health, Leicester University Medical School, and Medical Physics [D.H.E.], Leicester \\ Royal Infirmary, Leicester, England
}

\begin{abstract}
Eleven normal term infants undergoing respiratory assessment involving rebreathing to produce progressive hypercapnia were studied by Doppler ultrasound examination of an anterior cerebral artery during the procedure. A linear increase in end tidal carbon dioxide concentration from $4.5 \%$ to a maximum of $8.5 \%$ was documented during a period of 4-5 min rebreathing. A corresponding elevation of transcutaneous carbon dioxide tension was shown in the two infants monitored in this way. In all cases the Pourcelot index fell with rising end tidal carbon dioxide concentration. This fall in Pourcelot index was due to an increase in the diastolic frequency of the Doppler waveform. These results are consistent with the view that Pourcelot index correlates with cerebral vascular resistance distal to the site of recording. (Pediatr Res 20: 218-221, 1986)
\end{abstract}

\section{Abbreviations}

PI, Pourcelot index

$\mathrm{S}$, systolic frequency

$\mathrm{D}$, diastolic frequency

AUTC, area under the curve

The study of cerebral hemodynamics in the newborn infant by Doppler ultrasound is attractive because it is convenient, noninvasive, and apparently safe. There are a number of reports describing this technique in many different pathological situations $(1-10)$ but few which describe findings in normal babies $(11,12)$. There is little information on the hemodynamic processes that underlie changes in Doppler ultrasound readings from the cerebral vessels of newborn babies. It has been claimed that the pulsatility of Doppler waveforms recorded from these vessels correlates with cerebral vascular resistance $(11,13,14)$. There have been few attempts to validate this supposition. In adult animals a direct correlation between cerebral blood flow calculated from Doppler shift frequencies and that obtained by the microsphere method has been reported (15).

In animal studies $(16,17)$ change in blood flow velocity induced by hypercapnia and assessed by Doppler ultrasound correlated with changes in cerebral blood flow using the microsphere technique, but measures of the pulsatility of the Doppler waveform correlated only poorly in newborn dogs and not at all in piglets. Daven et al. (18) showed hypercapnia to be associated with a fall in pulsatility of the Doppler waveform in sick preterm infants being ventilated for respiratory disease. Griesen et al. (19) showed a relationship between Doppler variables and cerebral

Received August 19, 1985; accepted October 31, 1985

Correspondence and requests for reprints to Dr. M. I. Levene, Department of Child Health, Clinical Sciences Building, Leicester Royal Infirmary, P.O. Box 65, Leicester LE2 7LX, England. blood flow as measured by $133-X e n o n$ clearance in a small number of newborn infants. The only work we know of on human newborns specifically attempting to validate Doppler ultrasound examination of cerebral arteries using hypercapnia as a vasodilating stimulus failed to show a correlation between any Doppler parameter and the level of inspired carbon dioxide or the cerebral blood flow evaluated by the technique of transcephalic electrical impedance (20). The purpose of this study was to examine the effect of carbon dioxide induced cerebral vasodilation on anterior cerebral artery Doppler ultrasound waveforms and in particular to test the hypothesis that PI reflects cerebral vascular resistance.

\section{MATERIALS AND METHODS}

Eleven full-term healthy newborn infants aged 8 days or less were studied. No baby was considered to have any respiratory, neurological, or cardiovascular problem at any time prior to the study. The infants were undergoing respiratory function testing as normal controls which included an assessment of respiratory control involving carbon dioxide rebreathing (21). The rebreathing tests and Doppler examination had been approved by the hospital ethical committee, informed parental consent was obtained, and at least one parent was always present throughout the study. A close fitting face mask was applied over nose and mouth through which the infant breathed. Clinical and electrophysiological criteria (EOG, ECG, thoracic impedance, and single lead EEG) were recorded throughout to confirm that no change in sleep state occurred during the period of rebreathing. End tidal carbon dioxide concentration was measured by an infra-red spectrum analyzer in gas continuously sampled close to the nose. When the baby was asleep breathing air, a rebreathing circuit filled with $95 \%$ oxygen $5 \%$ carbon dioxide was switched in. This resulted in an initial fall in end tidal carbon dioxide concentration while equilibrium of the system occurred and thereafter a linear rise from $4.5 \%$ to a maximum of $8.5 \%$ over 4-5 min. In two infants simultaneous transcutaneous carbon dioxide tension measurements (Kontron $634 \mathrm{CO}_{2}$ module) were made at the time of rebreathing. Throughout the rebreathing period one anterior cerebral artery was insonated via the anterior fontanelle using a Sonicaid Vasoflow bidirectional Doppler unit operating at $4 \mathrm{MHz}$. The probe was maintained at a constant angle throughout each run and the resulting Doppler signals subjected to real time spectral analysis so as to allow continuous appraisal of both the sonogram and the auditory signal. This allowed the optimal signal to be maintained throughout. The signal was recorded on magnetic tape for later analysis by an Angioscan spectrum analyzer interfaced to a Vector Graphics 3100 microcomputer which extracted the maximum frequency envelope (Fig. 1). At various points during the rise in carbon dioxide level the waveforms of approximately 20 consecutive cardiac cycles were analyzed to give the following values: $S, D$, and PI, as shown in Figure 1. In seven infants intermittent 
indirect blood pressure measurements were attempted during rebreathing using an oscillometric device (Dinamap 847). However, this device frequently startled the baby so as to cause the rebreathing experiment to be abandoned. Doppler readings from the rebreathing episodes disturbed in this way were not analyzed. The Doppler readings analyzed all came from rebreathing periods in which the end tidal carbon dioxide concentration rose in a linear manner from $4.5 \%$ to at least $6.5 \%$. Rebreathing episodes were discontinued if a baby demonstrated more than the occasional minor limb, trunk, or head movement or if carbon dioxide concentration reached $8.5 \%$. The data were analyzed using the Spearman rank correlation test.

\section{RESULTS}

In all infants, undisturbed rebreathing produced a smooth linear increase in end tidal carbon dioxide concentration and, in the two babies on whom a transcutaneous electrode was used, a similar smooth increment in carbon dioxide tension was noted (Fig. 2). PI fell with increasing end tidal carbon dioxide concentration in all cases, reaching statistical significance in nine of the 11 babies (see Table 1). A fall in PI may be due either to a rise in $\mathrm{D}$ or a fall in $\mathrm{S}$ or a combination of both. During hypercapnia $\mathrm{D}$ increased in 10 of 11 babies and $\mathrm{S}$ increased in eight cases (Table 2). Thus the fall in PI with increasing carbon dioxide concentration was due to an elevation of $\mathrm{D}$ and not a fall in $\mathrm{S}$.

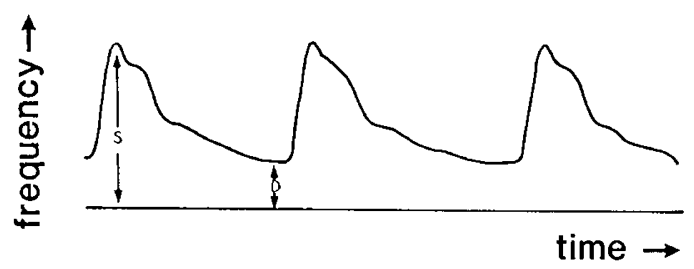

Fig. 1. Maximum frequency envelope of Doppler shift showing systolic frequency $(\mathrm{S})$ and diastolic frequency $(\mathrm{D}) . \mathrm{PI}=(\mathrm{S}-\mathrm{D}) / \mathrm{S}$.
Changes in mean flow velocity which are represented by changes in the AUTC of the Doppler waveform are a measure of changes in cerebral blood flow providing that the angle of insonation and the caliber of the insonated vessel remain constant. Pooling all the readings from different rebreathing episodes on each of the 11 babies, AUTC increased in 10 , the change being significant $(p<0.05)$ in five. The gradient of the linear regression lines for PI, S, D, and AUTC versus end tidal carbon dioxide are given in Table 2. Blood pressure measurements were difficult to obtain as many babies visibly startled when the oscillometric device triggered thereby invalidating both the blood pressure recording and the rebreathing experiment.

\section{DISCUSSION}

Carbon dioxide is a cerebral vasodilator (22) and hypercapnia therefore increases cerebral blood flow $(23,24)$. We have demonstrated that the linear increase in end tidal carbon dioxide concentration occurring during rebreathing was accompanied by

Table 1. The Spearman rank correlation coefficient ( $\rho$ ) for end tidal carbon dioxide concentration and $P^{*}$

\begin{tabular}{crcc}
\hline Baby & $n$ & $\rho$ & $p$ \\
\hline 1 & 19 & -0.78 & $<0.01$ \\
2 & 8 & -0.84 & $<0.01$ \\
3 & 5 & -0.93 & $<0.05$ \\
4 & 7 & -0.72 & $<0.05$ \\
5 & 10 & -0.59 & $<0.05$ \\
6 & 13 & -0.19 & $\mathrm{NS}$ \\
7 & 13 & -0.62 & $<0.05$ \\
8 & 17 & -0.48 & $<0.05$ \\
9 & 12 & -0.77 & $<0.01$ \\
10 & 7 & -0.13 & $\mathrm{NS}$ \\
11 & 18 & -0.73 & $<0.01$ \\
\hline
\end{tabular}

* The total number of readings for each baby $(n)$ was obtained from between one and three separate runs.

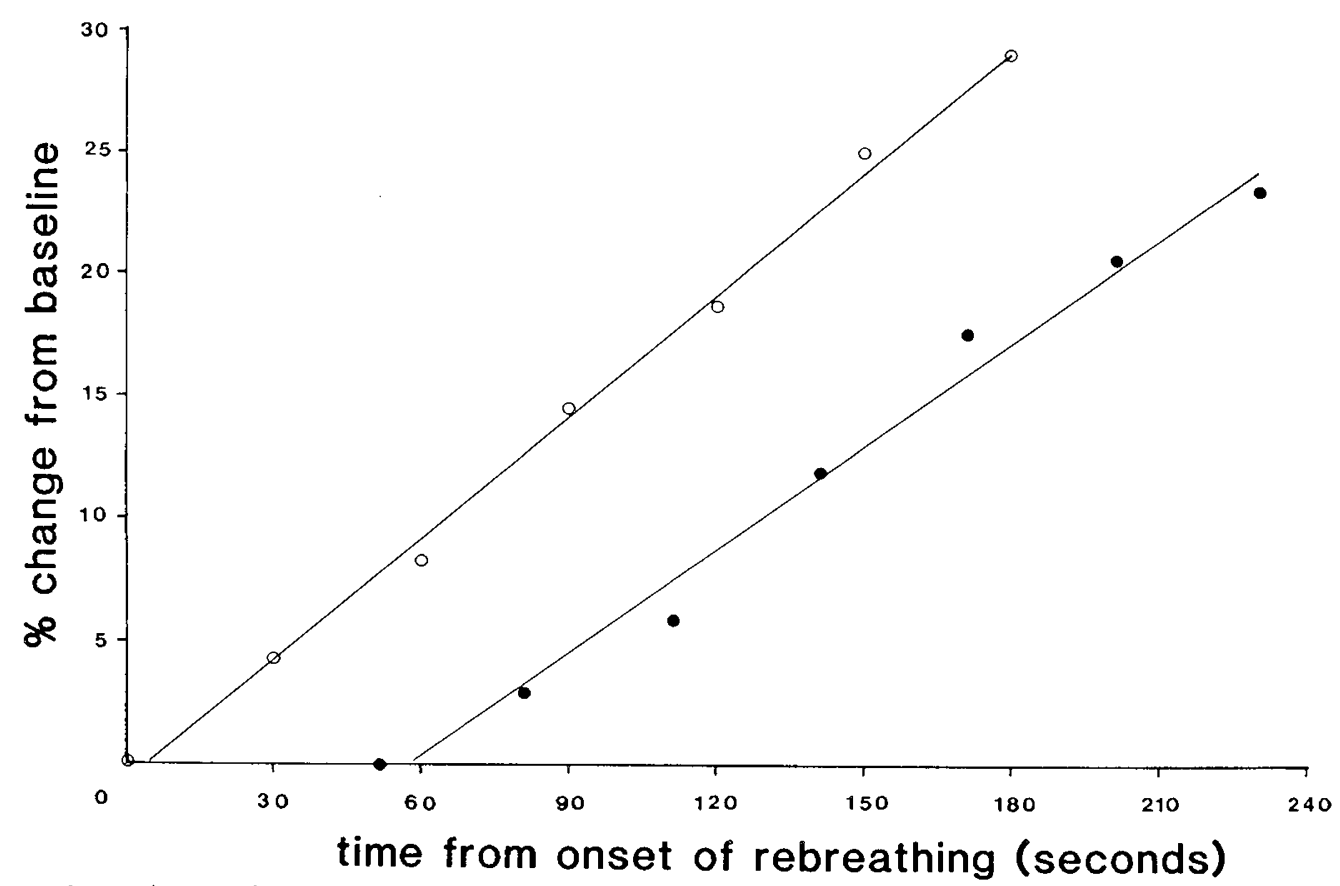

Fig. 2. Percentage change in end tidal carbon dioxide concentration (open circles) and transcutaneous carbon dioxide tension (filled circles) plotted against time from the start of rebreathing for one study. The delay in the rise of transcutaneous carbon dioxide tension is attributed to the characteristics of the transcutaneous electrode. A least squares best fit straight line is fitted to both sets of points to demonstrate the similarity in rates of climb. 
Table 2. The slope of the linear regression lines of PI, D, S, and AUTC versus end tidal carbon dioxide concentration*

\begin{tabular}{|c|c|c|c|c|c|c|}
\hline \multirow[b]{2}{*}{ Baby } & \multicolumn{2}{|c|}{$\begin{array}{l}\text { End tidal carbon } \\
\text { dioxide }\end{array}$} & \multicolumn{4}{|c|}{ Slope of regression line } \\
\hline & $\begin{array}{c}\text { Minimum } \\
\left(\% \mathrm{CO}_{2}\right)\end{array}$ & $\begin{array}{c}\text { Maximum } \\
\left(\% \mathrm{CO}_{2}\right)\end{array}$ & $\begin{array}{c}\mathrm{PI} \\
\left(1 / \% \mathrm{CO}_{2}\right)\end{array}$ & $\mathrm{D}$ & $\begin{array}{c}\mathrm{S} \\
\left(\mathrm{Hz} / \% \mathrm{CO}_{2}\right)\end{array}$ & AUTC \\
\hline 1 & 4.6 & 7.9 & -0.03 & 96 & 84 & 108 \\
\hline 2 & 6.0 & 8.5 & -0.03 & 32 & 17 & 27 \\
\hline 3 & 5.7 & 7.2 & -0.01 & 480 & 583 & 532 \\
\hline 4 & 5.0 & 7.0 & -0.02 & 44 & -14 & 54 \\
\hline 5 & 5.5 & 7.0 & -0.06 & 98 & 10 & 86 \\
\hline 6 & 4.5 & 7.0 & -0.01 & -23 & -71 & -18 \\
\hline 7 & 4.5 & 7.5 & -0.04 & 119 & 66 & 127 \\
\hline 8 & 4.5 & 8.5 & -0.01 & 87 & 168 & 128 \\
\hline 9 & 4.5 & 7.5 & -0.03 & 38 & -89 & 6 \\
\hline 10 & 5.0 & 6.5 & -0.01 & 29 & 53 & 32 \\
\hline 11 & 4.5 & 7.4 & -0.02 & 71 & 64 & 83 \\
\hline
\end{tabular}

* Each of the quantities in the final three columns is angle dependent but these slopes are included to demonstrate the extent of the changes encountered.

a linear rise in transcutaneous carbon dioxide tension. We therefore deduce that hypercapnia was occurring during our study and would be producing cerebral vasodilation with associated increases in cerebral blood flow velocity and blood flow. The use of changes in AUTC to assess changes in blood flow is only valid if the angle of insonation remains constant. In this study the angle of insonation was constant throughout a given rebreathing experiment but this could not be guaranteed for different rebreathing episodes on the same baby. The statistical analysis applied to AUTC is not intended to signify that AUTC is a valid parameter to use when the angle of insonation is not known to be constant. However, AUTC is widely used in such circumstances and thus it is noteworthy that the trends observed were in keeping with the postulated cerebral vasodilation produced by hypercapnia. In clinical situations where exact fixation of the probe is difficult and serial recordings are to be performed without the concomitant use of an imaging system, an angle independent expression of the results is to be preferred. Thus the need to validate the use of PI as an indicator of changes in cerebral vascular resistance.

The changes seen in the Doppler waveform may reflect events other than those occurring in the cerebral circulation distal to the site recording. An increase in cardiac output may affect velocity waveforms. Cardiac output may be altered by changes in heart rate or stroke volume. There was no significant trend in heart rate with hypercapnia in the babies in this study. It is not possible to deduce what changes, if any, were occurring in stroke volume. Little is known about the ability of newborn infants to alter myocardial contractility and therefore stroke volume (25). An increase in blood pressure has been reported by Perlman and Volpe (10) to be associated with an increase in cerebral blood flow velocity, but the infants studied were having suction of endotracheal tubes and therefore various stimuli may have caused an alteration in their cerebral hemodynamics. Blood pressure was not satisfactorily measured on the babies in our study. We are studying the effect of hypercapnia on blood pressure in babies with indwelling arterial catheters. Our preliminary observations (unpublished data) suggest that hypercapnia causes a more marked rise in systolic blood pressure than diastolic. This might be expected to have its main effect on systolic velocity whereas during rebreathing it was the diastolic velocity that showed the greater relative increase. The animal studies quoted earlier $(16,17)$ did not show significant changes in blood pressure with hypercapnia. Tominaga et al. (23) reported an increase in mean blood pressure with hypercapnia in adult men but there was no alteration in the increase in cerebral blood flow induced by hypercapnia when the elevation in blood pressure was blocked pharmacologically. That is to say, the increase in cerebral blood flow with hypercapnia was not dependent on elevation of the blood pressure. It thus seems unlikely that alterations in blood pressure, if they occurred, would have made a major contribution toward the changes in Doppler waveform observed in our study. The effect of hypercapnia on the systemic vasculature is complex although changes in resistance would mediate effects on the cerebral circulation through alterations in blood pressure.

Our results are in conflict with those of Costeloe et al. (20). This discrepancy may be due to a number of factors. First, our use of $4 \mathrm{MHz}$ (rather than $8 \mathrm{MHz}$ ) ultrasound gives better tissue penetration and is likely to result in more satisfactory Doppler signals. Second, spectral analysis of the signals is not subject to the considerable errors and artefacts of the zero crossing technique $(26,27)$ used by Costeloe et al. $(20)$ and many other workers to analyze Doppler waveforms. Third, in this study cerebral vasodilation was induced by a linear rise in carbon dioxide concentration from $4.5 \%$ up to a maximum of $8.5 \%$ which probably resulted in a more marked and consistent fall in cerebral vascular resistance than a single step increase from air to 2 or $3 \%$ carbon dioxide as used in the study of Costeloe $e t$ al. (20).

In conclusion, we have shown that hypercapnia-induced cerebral vasodilation resulted in a fall in PI due to an increase in diastolic frequency. These results are consistent with the hypothesis that PI does correlate with cerebral vascular resistance distal to the site of recording.

\section{REFERENCES}

1. Bada HS, Hajjar W, Chua C, Sumner DS 1979 Non invasive diagnosis of neonatal asphyxia and intra ventricular haemorrhage by Doppler ultrasound. J Pediatr 95:775-779

2. Peabody JL 1981 Mechanical ventilation of the newborn. Good news . . bad news Crit Care Med 9:710-713

3. Perlman JM, Hill A, Volpe JJ 1981 The effect of patent ductus arteriosus on flow velocity in the anterior cerebral arteries: ductal steal in the premature newborn infant. J Pediatr 99:767-771

4. Hill A, Perlman JM, Volpe JJ 1982 Relationship of pneumothorax to occurrence of intraventricular haemorrhage in the premature newborn. Pediatrics 69:144-149

5. Hill A, Volpe JJ 1982 Decrease in pulsatile flow in the anterior cerebral arteries in infantile hydrocephalus. Pediatrics 69:4-7

6. Lipman B, Serwer GA, Brazy JE 1982 Abnormal cerebral haemodynamics in preterm infants with patent ductus arteriosus. Pediatrics 69:778-781

7. Rosenkrantz TS, Oh W 1982 Cerebral blood flow velocity in infants with polycythemia and hyperviscosity: effects of partial exchange transfusion with Plasmanate. J Pediatr 101:94-98

8. McMenamin JB, Volpe JJ 1983 Doppler ultrasonography in the determination of neonatal brain death. Ann Neurol 14:302-307

9. Perlman JM, McMenamin JB, Volpe JJ 1983 Fluctuating cerebral blood flow velocity in respiratory distress syndrome. N Engl J Med 309:204-209

10. Perlman JM, Volpe JJ 1983 Suctioning in the preterm infant: effects on cerebral blood flow velocity, intra cranial pressure and arterial blood pressure. Pediatrics 72:329-334

11. Gray PH, Griffin EA, Drumm JE, Fitzgerald DE, Duignan NM 1983 Continuous wave Doppler ultrasound in evaluation of cerebral blood flow in neonates. Arch Dis Child 58:677-681

12. Archer LNJ, Evans DH, Levene MI 1985 Doppler ultrasound examination of the anterior cerebral arteries of normal newborn infants. The effect of postnatal age. Early Hum Dev 10:255-260

13. Pourcelot L 1976 Diagnostic ultrasound for cerebral vascular diseases. In Donald I, Levis S (eds) Present and Future of Diagnostic Ultrasound. Kooyker, Rotterdam, pp 141-147

14. Plainol $T$, Pourcelot L 1973 Doppler effect study of the carotid circulation. In: de Vleiger M, White DN, McCready VR (eds) Ultrasonics in Medicine. Elsevier, New York pp 104-111

15. Busija DW, Heistad DD, Marcus ML 1981 Continuous measurement of cerebral blood flow in anaesthetized cats and dogs. Am J Physiol 241:H228$\mathrm{H} 234$

16. Hansen NB, Stonestreet BS, Rosenkrantz $\Upsilon$, Oh W 1983 Validity of Doppler measurements of anterior cerebral artery blood flow velocity: correlation with brain blood flow in piglets. Pediatrics 72:526-531

17. Batton DG, Hellmann J, Hernandez MJ, Maisels MJ 1983 Regional cerebral blood flow, cerebral blood velocity and pulsatility index in newborn dogs. Pediatr Res 17:908-912

18. Daven JR, Milstein JM, Guthrie RD 1983 Cerebral vascular resistance in 
premature infants. Am J Dis Child 137:328 -331

19. Griesen G, Johansen K, Ellison PH, Frederiksen PS, Mali J, Friis-Hansen B 1984 Cerebral blood flow in the newborn infant: comparison of Doppler ultrasound and 133-Xenon clearance. J Pediatr 104:411-418

20. Costeloe K, Weindling AM, Tarrassenko L, Murphy D, Wellner JC, Rolfe P 1984 An attempt to validate the use of pulsatility index in the study of the newborn cerebral circulation. Biol Neonate 45:300 (abstr)

21. Taeusch HW, Carson S, Frantz ID, Milic-Emili J 1976 Respiratory regulation after elastic loading and $\mathrm{CO}_{2}$ rebreathing in normal term infants. J Pediatr 88: 102-111

22. Purves MJ 1978 Control of cerebral blood vessels: present state of the art. Ann Neurol 3:377-383

23. Tominaga S, Strandgaard S, Uemura K, Ito K, Kutsuzawa T, Lassen NA,
NaRamura $T 1976$ Cerebro vascular $\mathrm{CO}_{2}$ reactivity in normotensive and hypertensive men. Stroke 7:507-510

24. Hauge A, Thoresen M, Walloe L 1980 Changes in cerebral blood flow during hyperventilation and $\mathrm{CO}_{2}$-breathing measured transcutaneously in humans by a bi-directional, pulsed, ultrasound Doppler blood velocity meter. Acta Physiol Scand 110:167-173

25. Roberton NRC 1979 Perinatal physiology. In Godfrey S, Baum JD (eds) Clinical Paediatric Physiology. Blackwell Scientific Publications, Oxford, pp 134-192

26. Johnston KW, Maruzzo BC, Cobbold RSC 1977 Errors and artefacts of Doppler flow meters and their solution. Arch Surg 112:1335-1342

27. Lunt MJ 1975 Accuracy and limitations of the ultrasonic Doppler blood velocimeter and zero crossing detector. Ultrasound Med Biol 2:1-10 